\title{
Modelo preditivo de risco genético de fissura labial com ou sem fissura palatina não- sindrômica na população brasileira
}

\author{
Carolina de Oliveira Silva*, Renato Assis Machado, Ricardo D. Coletta.
}

\begin{abstract}
Resumo
Neste estudo, tivemos como objetivo determinar um modelo preditivo de risco genético para as fissuras labiais com ou sem fissura palatina não-sindrômicas (FLIPNS) na população brasileira, através de métodos machine learning. Inicialmente tivemos as fases de treinamento e validação das amostras, das quais $17 \mathrm{SNPs}$ demonstraram altos scores de importancia e 13 deles valores de p permutado significantes. Esse modelo contendo 13 SNPs deu origem a uma precisão maior que $90 \%$ de predição na classificação dos indivíduos com FLtPNS. Interações SNP-SNP significantes foram encontradas em IRF6 (rs642961), GRHL3 (rs41268753) e VAX1 (rs7078160). Nossos resultados

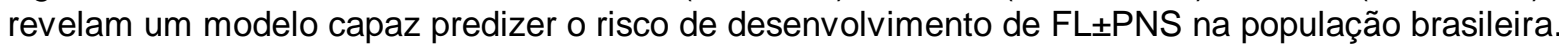

\section{Palavras-chave:}

Fissuras labiais com ou sem fissura palatina não-sindrômica, machine learning, risco genético.

\section{Introdução}

As fissuras labiais com ou sem fissura palatina nãosindrômica (FL士PNS) são as malformações craniofaciais mais comum em seres humanos. Embora múltiplos genes e loci são associados à sua etiologia, não há modelos que transformem estas informações em modelos de predição de risco para as FLtPNS. O objetivo deste estudo foi estabelecer um modelo preditivo de risco genético para as FL士PNS na população brasileira a partir de métodos de aprendizado de máquina (machine learning).

\section{Resultados e Discussão}

Após fases de treinamento (2/3 das amostras) e validação (1/3 da amostra), 17 SNPs demonstraram altos escores de importância e uma taxa de erro de aproximadamente 3\%, mas apenas 13 deles apresentaram valores significantes de $p$ permutado. O modelo contendo os 13 SNPs resultou em uma acurácia de predição na classificação dos indivíduos com $\mathrm{FL} \pm P N S$ superior a $90 \%$. Interações entre os SNPs localizados em IRF6 (rs642961), GRHL3

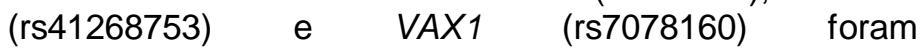
significantemente detectadas.

Tabela 1. Top 17 SNPs usando o escore de importância permutado baseada na análise de Random Forest.
Figura 1. Modelo Neural NetWork para discriminação de pacientes com FL $\pm P N S$ e controles

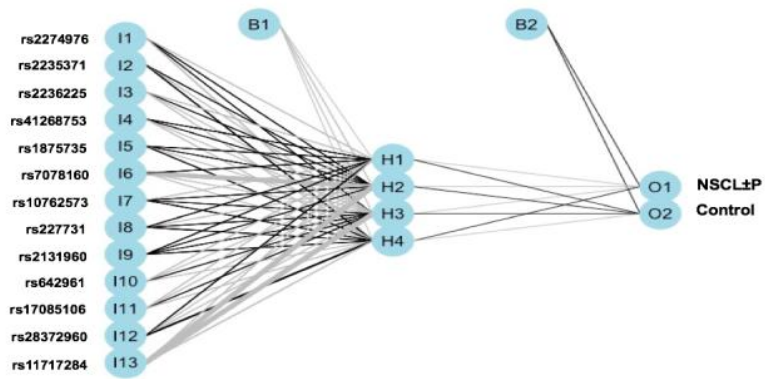

Tabela 2. Interações SNP-SNP baseados no modelo de redução de dimensionalidade multifatorial.

\begin{tabular}{llcc}
\hline SNP1 & SNP2 & $\begin{array}{c}\text { Valor de } \\
\mathbf{P}\end{array}$ & $\begin{array}{c}\text { Valor de P } \\
\text { Perm. }\end{array}$ \\
\hline rs17085106 (RHPN2) & rs7078160 (VAX1) & $2.98 \mathrm{e}-15$ & $<0.001$ \\
rs7078160 (VAX1) & rs227731 (17q22) & $3.59 \mathrm{e}-15$ & $<0.001$ \\
rs7078160 (VAX1) & rs28372960(TCOF1) & $7.19 \mathrm{e}-13$ & $<0.001$ \\
rs7078160 (VAX1) & rs642961 (IRF6) & $3.40 \mathrm{e}-12$ & $<0.001$ \\
rs17085106 (RHPN2) & rs28372960(TCOF1) & $5.35 \mathrm{e}-08$ & $<0.001$ \\
rs7078160 (VAX1) & rs41268753(GRHL3) & $7.72 \mathrm{e}-08$ & $<0.001$ \\
rs17085106 (RHPN2) & rs642961 (IRF6) & $3.59 \mathrm{e}-06$ & $<0.001$ \\
rs227731 (17q22) & rs2013162 (IRF6) & $3.64 \mathrm{e}-06$ & $<0.001$ \\
rs7086344 (VAX1) & rs227731 (17q22) & $5.24 \mathrm{e}-06$ & $<0.001$ \\
rs227731 (17q22) & rs10762573(VCL) & $3.88 \mathrm{e}-05$ & 0.001 \\
rs227731 (17q22) & rs2131960 (VCL) & $8.72 \mathrm{e}-05$ & 0.004 \\
rs227731 (17q22) & rs2274976 (MTHFR) & $3.00 \mathrm{e}-04$ & $<0.001$ \\
rs227731 (17q22) & rs2235371 (IRF6) & $3.25 \mathrm{e}-04$ & 0.001 \\
rs227731 (17q22) & rs28372960(TCOF1) & $3.80 \mathrm{e}-04$ & $<0.001$ \\
\hline
\end{tabular}

\section{Conclusões}

Nossos resultados apontam um modelo capaz predizer o risco de desenvolvimento de FLェPNS na população brasileira. Embora validação é garantida, este painel pode gerar um impacto muito grande na prática clínica, com potencial inovador e translacional.

\section{Agradecimentos}

Li, Q., Kim, Y., Suktitipat, B., Hetmanski, J.B., Marazita, M.L., Duggal, P., Beaty, T.H., e Bailey-Wilson, J.E. Genet Epidemiol. 2015, 39, 385-94.

Zhang, S.J., Meng, P., Zhang, J., Jia, P., Lin, J., Wang, X., Chen, F., e Wei, X Genomics Proteomics Bioinformatics. 2018, 16, 354-364. 